\title{
Effect of Long-time Heating for Polyvinyl Chloride and Polypropylene Resin Pellet Certified Reference Materials for Heavy Metal Analysis
}

\author{
Masaki OHATA \\ Inorganic Standards Group, Research Institute for Material and Chemical Measurement, National Metrology \\ Institute of Japan (NMIJ), National Institute of Advanced Industrial Science and Technology (AIST), \\ AIST Tsukuba Central 3-9, 1-1-1 Umezono, Tsukuba, Ibaraki 305-8563, Japan
}

\begin{abstract}
The effect of long-time heating for both polyvinyl chloride (PVC) and polypropylene (PP) resin pellet certified reference materials (CRMs) for heavy metal analysis, which contained $\mathrm{Cd}, \mathrm{Cr}, \mathrm{Hg}$ and $\mathrm{Pb}$, was examined in the present study. The temperature of the drying oven was $80^{\circ} \mathrm{C}$, which was used for drying these CRMs before analysis, and the long-time heating was carried out for up to $480 \mathrm{~h}$. As a result, a relative decrease in mass of $c a .0 .3 \%$ was observed for both CRMs. Moreover, a decrease in concentration of $c a$. $10 \%$ was observed for $\mathrm{Cr}$, even though the concentrations for other elements did not change during the long-time heating. Since the chemical form of $\mathrm{Cr}$ was an organometallic compound with lower melting point, it was considered that concentration decreased due to the heat.
\end{abstract}

Keywords Long-time heating, PVC resin pellet CRM, PP resin pellet CRM, organometallic compound, chromium acetylacetonate

(Received March 4, 2016; Accepted May 12, 2016; Published September 10, 2016)

\section{Introduction}

The directive on the restriction of the use of hazardous substances in electrical and electronic equipment (RoHS) is one of the directives of European Union (EU) that became effective in July 2006. ${ }^{1,2}$ There was a great upheaval in Japan, because the export of electrical and electronic equipment to EU would not be possible unless the requirements of the directive were met. Since the parts and the final products of electrical and electronic equipment are made from raw materials and by assembling the parts, respectively; any relevant industries and societies could not remain indifferent to the directive. The targeted hazardous substances were $\mathrm{Cd}, \mathrm{Cr}(\mathrm{VI}), \mathrm{Hg}, \mathrm{Pb}, \mathrm{PBB}$ (poly-brominated biphenyl) and PBDE (poly-brominated diphenyl ether) and the threshold values were 100 and $1000 \mathrm{mg} \mathrm{kg}^{-1}$ for $\mathrm{Cd}$ and other substances, respectively. It was well known that plastic materials were widely used in electrical and electronic equipment; therefore, standard analytical procedures $^{3}$ and certified reference materials (CRMs) of hazardous substances in plastics were demanded from relevant industries and societies. In line with the requirements, National Metrology Institute of Japan (NMIJ) has been made efforts to develop plastic CRMs for heavy metal analysis with respect to RoHS directive. ${ }^{4-13}$ So far, acrylonitrile-butadiene-styrene (ABS), ${ }^{4-7}$ polyvinyl chloride $(\mathrm{PVC})^{8}$ and polypropylene $(\mathrm{PP})^{8,10-13}$ resin CRMs for the determination of $\mathrm{Br}, \mathrm{Cd}, \mathrm{Cr}, \mathrm{Hg}$ and $\mathrm{Pb}$ have been developed. These plastic CRMs were pellet or disk forms and were developed for chemical analysis $\mathrm{s}^{4,8,10-12}$ or X-ray fluorescence spectrometry, ${ }^{5-7,9,13}$ respectively. A X-ray fluorescence (XRF) spectrometry is expected for direct and speedy analysis of the hazardous substances in electrical and electronic equipment ${ }^{14-17}$ and also described in the IEC 62321 as a screening method with respect to RoHS directive. ${ }^{3}$ However, the loss of elements in plastics during XRF measurement was a concern and reported for an organometallic compound of $\mathrm{Hg}$ in plastic CRM due to its volatility, ${ }^{14}$ which might result in serious analytical error for the determination of hazardous substances. In our previous study, we also observed the loss of $\mathrm{Cr}$ from the PP resin disk CRM (NMIJ CRM 8136-a) for long-time measurements by XRF spectrometry. ${ }^{13}$ The temperature observed at the surface of the PP resin disk CRM was $c a .90^{\circ} \mathrm{C}$ after $1 \mathrm{~h}$ measurement by wavelength dispersive XRF (WDXRF) spectrometer and the loss of $c a .10 \% \mathrm{Cr}$ was observed during the long-time measurement for $120 \mathrm{~h}$ from the side of the surface irradiated by X-ray. Since the chemical forms of $\mathrm{Cr}$ for both inorganic and organometallic compounds were mixed in the PP resin disk CRM, the organo one was considered to be lost by the heating from the long-time X-ray irradiation. If the heat is the main source for the loss of elements, it is considered that the similar phenomenon can be observed during drying procedure for a long-time using a drying oven.

In the present study, the effect of long-time heating was examined for both PVC and PP resin pellet CRMs to explore the source of the loss of elements. These CRMs were heated at $80^{\circ} \mathrm{C}$ in a drying oven, which was the temperature used for drying these CRMs before analysis, and the changes in mass of the CRMs and concentrations of elements were evaluated for long-time heating up to $480 \mathrm{~h}$. 


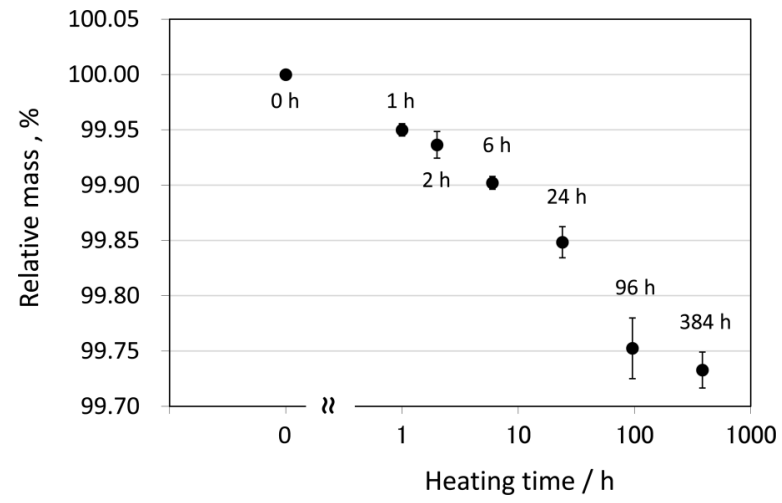

Fig. 1 Relative change in mass of PVC resin pellet CRM as a function of heating time at $80^{\circ} \mathrm{C}$ for up to $384 \mathrm{~h}$ (16 days). The initial mass of the PVC resin pellet CRM examined was $0.5 \mathrm{~g}$. The bar indicated shows standard deviation $(n=3)$.

\section{Experimental}

\section{Sample and instrumentation}

The PVC and PP resin pellet CRMs examined in the present study were NMIJ CRM 8123-a and 8133-a, respectively, which were developed by NMIJ (Tsukuba, Ibaraki, Japan). ${ }^{8,18,19}$ The masses of one pellet were $c a .30 \mathrm{mg}$ and $c a .10 \mathrm{mg}$ for PVC and $\mathrm{PP}$ resin pellet CRMs, respectively. ${ }^{8}$ The chemical forms of $\mathrm{Cd}$, $\mathrm{Hg}$ and $\mathrm{Pb}$ contained in both the CRMs were inorganic compounds such as cadmium oxide $(\mathrm{CdO})$, mercury sulfide $(\mathrm{HgS})$ and lead chromate $\left(\mathrm{PbCrO}_{4}\right)$, respectively. ${ }^{8,18,19}$ On the other hand, the chemical forms of $\mathrm{Cr}$ contained in both the CRMs were not only $\mathrm{PbCrO}_{4}$ but also chromium acetylacetonate $\left(\mathrm{Cr}\left(\mathrm{C}_{5} \mathrm{H}_{7} \mathrm{O}_{2}\right)_{3}\right)$ which can be expressed as $\mathrm{Cr}(\mathrm{acac})_{3}$, as inorganic and organometallic compounds, respectively; ${ }^{8,18,19}$ in order to increase total concentration of $\mathrm{Cr}$ to be closer to threshold value of $1000 \mathrm{mg} \mathrm{kg}^{-1}$, even though hexavalent chromium $(\mathrm{Cr}(\mathrm{VI}))$ was a subject in RoHS directive. ${ }^{1-3}$ The melting points of $\mathrm{CdO}$, $\mathrm{HgS}, \mathrm{PbCrO}_{4}$ and $\mathrm{Cr}(\mathrm{acac})_{3}$ are $900-1000,580,844$ and $210^{\circ} \mathrm{C}$, respectively; and the concentrations of $\mathrm{Cd}$ and other elements in both the CRMs are $c a .95 \mathrm{mg} \mathrm{kg}^{-1}$ and $c a .950 \mathrm{mg} \mathrm{kg}^{-1}$, respectively. $8,18,19$ A drying oven with maximum temperature of $250^{\circ} \mathrm{C}$ was used for long-time heating at $80^{\circ} \mathrm{C}$ in the present study. The heating temperature of $80^{\circ} \mathrm{C}$ is the drying temperature for these pellet $\mathrm{CRMs}^{8,18,19}$ to remove any moisture before analysis. The heating temperature was also close to the temperature of $c a .90^{\circ} \mathrm{C}$ observed at the surface of the PP resin disk CRM (NMIJ CRM 8136-a) after $1 \mathrm{~h}$ measurement by WDXRF spectrometer in our previous study. ${ }^{13}$ Approximately $0.5 \mathrm{~g}$ of both the pellet CRMs was weighed accurately by electric valance (AX 205, Mettler-Toledo International Inc.) and heated in the drying oven at $80^{\circ} \mathrm{C}$. After the heating, the mass and the concentrations of elements were measured. In case of mass measurement, the electric valance was used to weigh the mass of the CRMs. The concentrations of elements were determined by inductively coupled plasma mass spectrometry (ICPMS) with microwave acid digestion procedure which was along the analytical procedure described in Refs. 4 and 8.

\section{Results and Discussion}

Figure 1 shows the relative change in the mass of PVC resin pellet $\mathrm{CRM}$ as a function of heating time at $80^{\circ} \mathrm{C}$ for up to
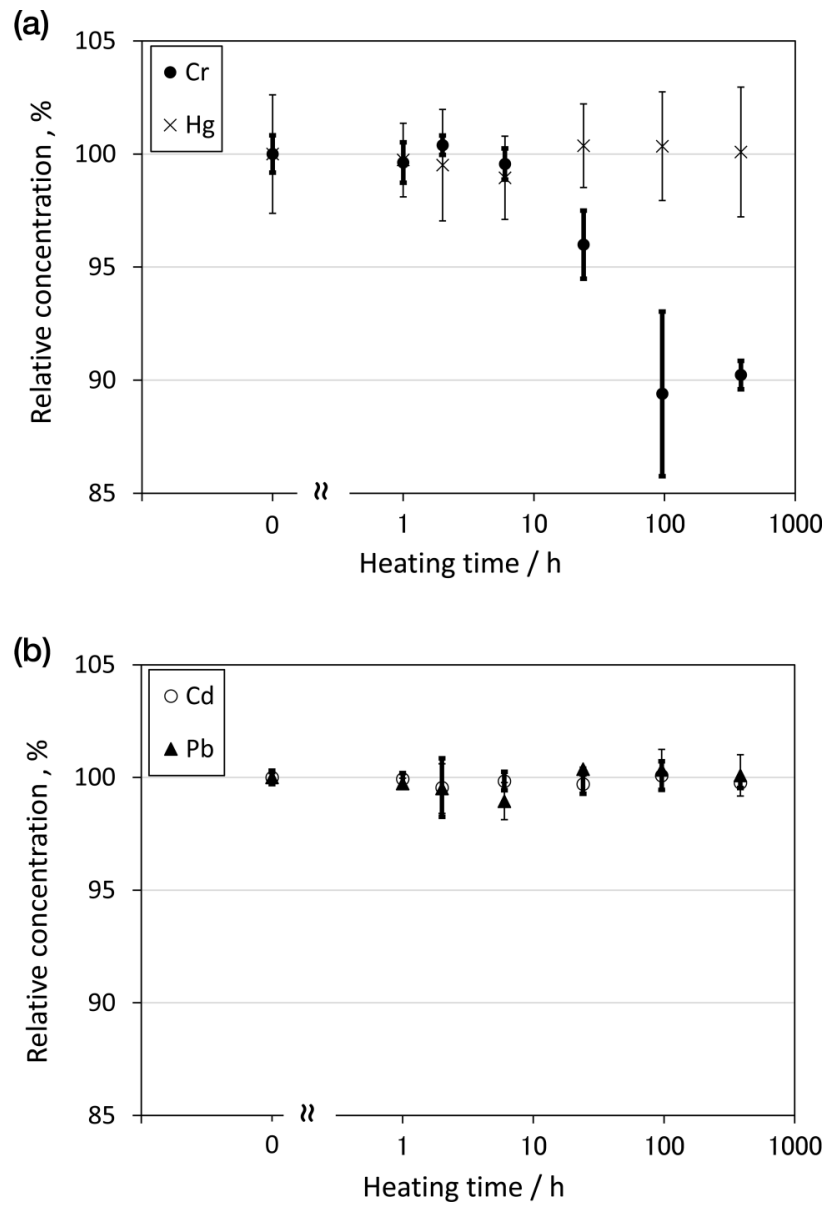

Fig. 2 Relative change in concentrations for (a) either $\mathrm{Cr}$ or $\mathrm{Hg}$ and (b) either $\mathrm{Cd}$ or $\mathrm{Pb}$ in PVC resin pellet CRM as a function of heating time at $80^{\circ} \mathrm{C}$ for up to $384 \mathrm{~h}$ (16 days). The relative concentrations obtained were normalized with respect to the initial concentrations of each element, which were normalized as $100 \%$. The bar indicated shows standard deviation $(n=3)$.

$384 \mathrm{~h}$ (16 days). The decrease in the mass was observed and it was ca. $0.25 \%$ until the heating for $96 \mathrm{~h}$ (4 days). The decrease in the mass remained almost constant at $0.25-0.28 \%$ from 96 to $384 \mathrm{~h}$. From the results, it was considered that the change in the mass of PVC resin pellet CRM was not so large; therefore, concentration of elements was expected to remain constant during the long-time heating. Figure 2 shows the change in concentrations of elements in PVC resin pellet CRM as a function of the heating time. It could be seen from Fig. 2, only the decrease in the concentration of $\mathrm{Cr}$ was observed even though the other elements did not show any loss during the heating for a long-time. The relative decrease in the concentration of $\mathrm{Cr}$ was $c a .10 \%$ after the heating for $96 \mathrm{~h}$. The loss of $\mathrm{Cr}$ was considered to be dependent on its chemical form, which resulted in the loss of $\mathrm{Cr}$ during the long-time heating. A similar examination was also carried out for PP resin pellet CRM as listed in Table 1. In case of the PP resin pellet CRM, relative decreases in the mass and the concentration of $\mathrm{Cr}$ observed were $c a .0 .3 \%$ and $c a .10 \%$, respectively, during the heating time for $480 \mathrm{~h}$ (20 days). Since the chemical forms of $\mathrm{Cr}$ in both the CRMs were $\mathrm{PbCrO}_{4}$ and $\mathrm{Cr}(\mathrm{acac})_{3}$ whose melting points were 844 and $210^{\circ} \mathrm{C}$, respectively; the organometallic compound of $\mathrm{Cr}(\mathrm{acac})_{3}$ was considered to be lost during the heating for a long-time. In our previous study, the loss of 
Table 1 Relative changes in the mass of PP resin pellet CRM and the concentration of elements after heating at $80^{\circ} \mathrm{C}$ for $480 \mathrm{~h}$

\begin{tabular}{cc}
\hline & Relative change, \% \\
\cline { 2 - 2 } Mass $^{\mathrm{a}}$ & $99.72 \pm 0.07$ \\
\hline $\mathrm{Cd}$ & $99.6 \pm 0.5$ \\
$\mathrm{Cr}$ & $89.7 \pm 4.6$ \\
$\mathrm{Hg}$ & $100.9 \pm 0.8$ \\
$\mathrm{~Pb}$ & $100.0 \pm 1.0$ \\
\hline
\end{tabular}

a. Initial mass of the PP resin pellet CRM examined was $0.5 \mathrm{~g}$. The value indicated after \pm shows standard deviation $(n=4)$.

ca. $10 \%$ Cr from the PP resin disk CRM (NMIJ CRM 8136-a), which was prepared from the PP resin pellet CRM (NMIJ CRM 8133-a) examined in the present study, was observed during long-time measurements for $120 \mathrm{~h}$ (5 days) by WD-XRF spectrometer. ${ }^{13}$ The temperature observed at the surface of the $\mathrm{PP}$ resin disk CRM was $\mathrm{ca} .90^{\circ} \mathrm{C}$ after $1 \mathrm{~h}$ measurement by WD-XRF spectrometer, which temperature was close to the drying temperature of $80^{\circ} \mathrm{C}$ examined in the present study. Although the surface areas between the pellet and the disk CRMs were different, the loss of similar amounts of $\mathrm{Cr}$ ( $c a$. $10 \%)$ was observed for both $120 \mathrm{~h}$ (5 days) measurement by WD-XRF spectrometer as in our previous study and the longtime heating for $480 \mathrm{~h}$ (20 days) as listed in Table 1. Moreover, since the loss of $\mathrm{Cr}$ in the disk CRM was observed from the side of the surface irradiated by X-ray in our previous study, it could be considered that the loss occurred predominantly from the surface area compared to the inside for both pellet and disk CRMs. From these results, the cause of the loss of $\mathrm{Cr}$ could be considered to be the heat and the amount of loss became constant after the heating for a few days since the loss occurred predominantly from the surface of the plastics. The similar phenomena may be observed for other plastic materials if they contain similar organometallic compounds. It was also considered that the loss of $c a .10 \% \mathrm{Cr}(\mathrm{acac})_{3}$ corresponded to a loss of $c a .0 .05 \%$ of mass for both the CRMs. The loss of the mass observed for pellet CRMs was larger than that speculated from the loss of $\mathrm{Cr}(\mathrm{acac})_{3}$. It was considered that both CRMs contained additives such as ultra violet absorber, hindered amine light stabilizer and anti-oxidation reagents to keep the resin stable, even though their chemical forms and concentrations were not known. Consequently, the additives were considered to be lost during the long-time heating examined in the present study.

\section{Conclusions}

The effect of long-time heating for both PVC and PP resin pellet CRMs for heavy metal analysis was examined in the present study. The relative decreases in the mass of $c a .0 .3 \%$ and the concentration of $\mathrm{ca} .10 \%$ for only $\mathrm{Cr}$ were observed, even though the concentrations for other elements did not change during the long-time heating. The organometallic compound of $\mathrm{Cr}$ with lower melting point resulted in the loss of $\mathrm{Cr}$ by the heating for a long-time. Although the loss of mass observed for both CRMs could not be explained by only the loss of $\mathrm{Cr}(\mathrm{acac})_{3}$, the additives contained were also considered to be lost during the long-time heating. Since the heat was considered to be generated during the drying procedure as well as the measurements by XRF spectrometry demonstrated in previous studies, ${ }^{13,14}$ it should be noted that there could be a loss of elements if the plastics measured contained organometallic compounds, which could result in serious analytical error for accurate determination of elements in plastics.

\section{References}

1. Directive 2002/95/EC of the European parliament and of the council of 27 January 2003, on the restriction of the use of certain hazardous substances in electrical and electronic equipment, Official Journal of European Union, 13. 2. 2003.

2. Directive $2011 / 65 / \mathrm{EC}$ of the European parliament and of the council of 8 June 2011, on the restriction of the use of certain hazardous substances in electrical and electronic equipment (recast), Official Journal of European Union, 1. 7. 2011.

3. IEC 62321, International Standard: Electrotechnical products-Determination of levels of six regulated substances (lead, mercury, cadmium, hexavalent chromium, polybrominated biphenyls, polybrominated diphenyl ethers), ed. 1.0, 2008.

4. M. Ohata, M. Kurahashi, and A. Hioki, Bunseki Kagaku, 2008, 57, 417.

5. M. Kurahashi, T. Kidokoro, M. Ohata, S. Matsuyama, S. Kinugasa, and A. Hioki, Advances in X-ray Chemical, Analysis, Japan, 2009, 40, 203.

6. M. Ohata, T. Kidokoro, M. Kurahashi, and A. Hioki, Bunseki Kagaku, 2010, 59, 903.

7. M. Ohata, T. Kidokoro, and A. Hioki, Anal. Sci., 2012, 28 , 1105.

8. M. Ohata and A. Hioki, Anal. Sci., 2013, 29, 239.

9. M. Ohata and N. Matsubayashi, Spectrochim. Acta, Part B, 2014, 93, 14

10. M. Ohata and T. Miura, Anal. Chim. Acta, 2014, 837, 23.

11. T. Miura, R. Okumura, Y. Iinuma, S. Sekimoto, K. Takamiya, M. Ohata, and A. Hioki, J. Radioanal. Nucl. Chem., 2015, 303, 1417.

12. A. Wada, T. Miura, M. Ohata, and A. Hioki, Bunseki Kagaku, 2015, 64, 543.

13. M. Ohata and T. Kidokoro, Anal. Sci., 2015, 31, 855.

14. K. Nakano, T. Nakamura, I. Nakai, A. Kawase, M. Imai, M. Hasegawa, Y. Ishibashi, I. Inamoto, K. Sudou, M. Kozaki, A. Tsuruta, A. Ono, K. Kakita, and M. Sakata, Anal. Sci., 2006, 22, 1265.

15. C. Mans, S. Hanning, C. Simons, A. Wegner, A. Janßen, and M. Kreyenschmidt, Spectrochim. Acta, Part B, 2007, 62,116

16. M. Kimura, K. Nakano, and T. Nakamura, Bunseki Kagaku, 2008, 57, 411 .

17. C. Mans, C. Simons, S. Hanning, A. Janßen, D. Alber, M. Radtke, U. Reinholz, A. Bühler, and M. Kreyenschmidt, $X$-ray Spectrom., 2009, 38, 52.

18. https://www.nmij.jp/english/service/C/crm/70/8123a_en.pdf. 19. https://www.nmij.jp/english/service/C/crm/70/8133a_en.pdf. 